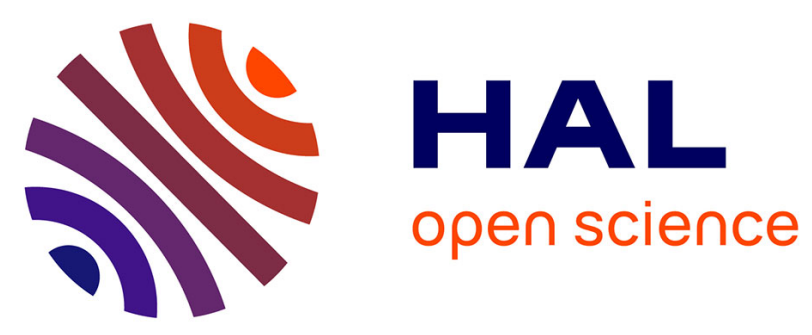

\title{
LOW TEMPERATURE ULTRASONIC ATTENUATION IN NEUTRON-IRRADIATED QUARTZ VERSUS THE INDUCED MASS-DENSITY CHANGES
}

\author{
A. Vanelstraete, C. Laermans, J. Cornelis
}

\section{To cite this version:}

A. Vanelstraete, C. Laermans, J. Cornelis. LOW TEMPERATURE ULTRASONIC ATTENUATION IN NEUTRON-IRRADIATED QUARTZ VERSUS THE INDUCED MASS-DENSITY CHANGES. Journal de Physique Colloques, 1987, 48 (C8), pp.C8-531-C8-537. 10.1051/jphyscol:1987883 . jpa00227187

\section{HAL Id: jpa-00227187 https://hal.science/jpa-00227187}

Submitted on 1 Jan 1987

HAL is a multi-disciplinary open access archive for the deposit and dissemination of scientific research documents, whether they are published or not. The documents may come from teaching and research institutions in France or abroad, or from public or private research centers.
L'archive ouverte pluridisciplinaire HAL, est destinée au dépôt et à la diffusion de documents scientifiques de niveau recherche, publiés ou non, émanant des établissements d'enseignement et de recherche français ou étrangers, des laboratoires publics ou privés. 
LOW TEMPERATURE ULTRASONIC ATTENUATION IN NEUTRON-IRRADIATED QUARTZ VERSUS THE INDUCED MASS-DENSITY CHANGES

\author{
A. VANELSTRAETE, C. LAERMANS and J. CORNELIS* \\ K.U. Leuven, Dept. Natuurkunde, V.S.H.D., B-3030 Leuven, \\ Belgium \\ "Physics Dept., SCK/CEN, B-2400 MOI, Belgium
}

\title{
Résumé
}

Ces mesures sont une extension d'une étude précédente de l'atténuation ultrasonore dans le quartz irradié aux neutrons vers des températures plus basses $(0.3 \mathrm{~K})$. Les mesures ont été faites dans la gamme de fréquence $300-650 \mathrm{MHz}$ et de doses

$1 \times 10^{18}$ à $26 \times 10^{18} \mathrm{n} / \mathrm{cm}^{2}(\mathrm{E} \geqq 0.3 \mathrm{MeV})$. Le comportement ultrasonore est typique pour l'existence des systèmes à deux niveaux: une loi en $\mathrm{T}^{3}$ aux plus basses températures, qui graduellement change vers une atténuation indépendente de $T$. La densité a été mesurée et une comparaíson entre le paramètre typique $\overline{\mathrm{P}}_{\gamma_{\ell}^{2}}$ des systèmes à deux niveaux et la variation relative de densité, effectuée par l'irradiation aux neutrons a été faite. Pour des doses assez faibles, considérées ici, une relation linéaire a été observée.

\section{Abstract}

Previous ultrasonic attenuation measurements in neutron-irradiated quartz are extended to lower temperatures $(0.3 \mathrm{~K})$. The measurements were performed for different frequencies $(300-650 \mathrm{MHz})$ and doses $\left(1 \times 10^{18}\right.$ to $\left.26 \times 10^{18} \mathrm{n} / \mathrm{cm}^{2} ; \mathrm{E} \geqq 0.3 \mathrm{MeV}\right)$. The ultrasonic behaviour is typical for the existence of two-level systems (TLS) : a $\mathrm{T}^{3}$-law at the lowest temperatures which gradually levels off to a temperature independent attenuation. Mass density measurements were done and a comparison was made between the typical parameters $\overline{\mathrm{P}}_{\gamma}^{2}$ of the TLS and the relative mass density change induced by the irradiation. For these rather low neutron doses, a linear relation is observed.

\section{Introduction}

At low temperatures amorphous solids exhibit anomalous dynamic properties which can be accounted for by the existence of configurational tunnelling states [1]. These centres couple strongly to phonons and dominate the behaviour of specific heat, thermal conductivity and ultrasonic attenuation at low temperatures, as well as other low temperature properties. [2]. These tunnelling states are successfully described as two-level systems (TLS) [3] and the low temperature anomalies can phenomenologically be explained in the framework of the tunnelling model [1]. In spite of the fact that these anomalies are universally found in the many glasses studied until now, virtually nothing is known about the microscopic origin of these states. In order to contribute to this study, crystalline solids with defects, such as irradiated crystals, have been investigated. The key idea to study defective crystals is that crystalline environments of a defect are easier to study than the random networks of the glasses. Studies in neutron-irradiated quartz of the acoustic saturation [4], ultrasonic absorption [5] and velocity [6], thermal conductivity [7] and specific heat [8], revealed similar anomalies as in amorphous solids. They could be explained by the tunnelling model with a density of states of TLS which is smaller than in vitreous silica and which increases with neutron dose. 
So far, results of attenuation studies, concerning the TLS in neutron-irradiated quartz were allways presented as a function of neutron dose. However, there are some difficulties of using dose as a parameter. Indeed, different reactor facilities use a different fluxcalibration and in addition, there are differences in the energyspectra of the fast neutrons. Therefore, comparison between data obtained in samples irradiated in different reactor facilities may lead to totally wrong conclusions, allthough it is frequently done. In neutron-irradiated quartz the mass density is a better parameter for the induced damage than the neutron dose. Upon neutron-irradation, quartz gradually evolves to an amorphous form of $\mathrm{SiO}_{2}$, with a mass density being about $15 \%$ lower than that of the crystal [9]. The purpose of this article is twofold. On the one hand we report new ultrasonic attenuation data, an extension to lower temperatures of previous data [5]. On the other hand our mass density data on our neutron-irradiated samples are reported and the results of the ultrasonic studies are given as a function of the mass density changes. Since the change of the mass density is also a measure for the damage induced by the neutrons, the results of the ultrasonic studies are also discussed in view of these changes. It concerns a systematic study in the range of rather low neutron doses $\left(1 \times 10^{18} \mathrm{n} / \mathrm{cm}^{2}\right.$ to $26 \times 10^{18} \mathrm{n} / \mathrm{cm}^{2}(\mathrm{E} \geqq 0.3 \mathrm{MeV})$ ).

\section{Sample characterisation and experimental techniques}

Synthetic quartz samples, $x$-cut and originating from the same quartz block, were shaped into $8 \mathrm{~mm}$ long cylindrical rods with $3 \mathrm{~mm}$ diameter. The end faces were polished optically flat and parallel for ultrasonic studies. Neutron activation analysis yielded as impurity content in $\mu \mathrm{g} / \mathrm{g}$ :

$\begin{array}{llllllllll}\mathrm{Na} & 2.3 ; & \mathrm{Fe} & 0.7 & ; & \mathrm{Ga} & 0.06 ; & \mathrm{Cr} & 0.0016 ; \\ \mathrm{C} 1 & 9.8 ; & \mathrm{Zn} & 0.4 ; & \mathrm{Sb} & 0.06 & ; & \mathrm{Co} & 0.0022 .\end{array}$

The Al-impurity-content was below detectable limit which is $10 \mu \mathrm{g} / \mathrm{g}$. Four samples were irradiated up to a fast neutron dose ( $E \geqq 0.3 \mathrm{MeV}$ ) indicated in Table 1 , in the reactor of SCK/CEN, Mol. The third column refers to calibration of fast neutron flux for $E \geqq 0.1 \mathrm{MeV}$.

Table 1 : samples and respective doses

\begin{tabular}{lcc} 
Sample & Dose $\left(\mathrm{n} / \mathrm{cm}^{2}\right): E \geqq 0.3 \mathrm{MeV}$ & Dose $\left(\mathrm{n} / \mathrm{cm}^{2}\right): E \geqq 0.1 \mathrm{MeV}$ \\
\hline N2 & $0.85 \times 10^{18}$ & $1.36 \times 10^{18}$ \\
N3 & $6.6 \times 10^{18}$ & $1.06 \times 10^{19}$ \\
K2N3 & $1.2 \times 10^{19}$ & $2.0 \times 10^{19}$ \\
N5 & $2.6 \times 10^{19}$ & $4.1 \times 10^{19}$
\end{tabular}

The mass density of the irradiated samples and of an unirradiated one was measured, making use of a hydrostatic method. In the well-known Archimedes formula for the determination of the density:

$$
\rho=\rho_{\text {oil }} \frac{W_{v}}{W_{v}-W_{0}}
$$

with $\mathrm{W}_{\mathrm{v}}$ : weight of the sample in vacuum

$W_{0}$ : 'weight of the sample in an oil

the weight of the sample in vacuum is the sum of the weight of the sample in air 
and its Archimedes force in air:

$$
\mathrm{W}_{\mathrm{v}}=\mathrm{W}_{\text {air }}+\underset{\text { arch }}{\mathrm{F}_{\text {air }}} \text { with } \mathrm{F}_{\text {arch. }} \ll \mathrm{W}_{\text {air }}
$$

To take into account the Archimedes force in air, a first order approximation was used, leading to the following expression:

$$
\begin{aligned}
& \rho=\rho^{0}+\rho_{\text {air }}\left(1-\frac{\rho^{0}}{\rho_{\text {oil }}}\right) \\
& \text { with } \rho^{0}=\frac{W_{\text {air }} \rho_{\text {oil }}}{W_{\text {air }}-W_{o}}
\end{aligned}
$$

The weight of the sample in oil was determined by suspending the sample in the oil and by subtracting the weight of the suspension wire. As our samples are very small, the weighings had to be accurate to within $2 \times 10^{-5} \mathrm{~g}$. The measurements were performed at a temperature of $25^{\circ} \mathrm{C}$, fixed to within $0.1^{\circ} \mathrm{C}$.

Previous ultrasonic attenuation measurements [5] $(1.4 \mathrm{~K}$ to $300 \mathrm{~K})$ were extended to lower temperatures $(0.3 \mathrm{~K})$. The longitudinal ultrasonic attenuation was measured for different frequencies ( 300 to $650 \mathrm{MHz}$ ) and neutron doses, using the pulse echo technique. An electromagnetic pulse of about $1 \mu \mathrm{s}$ and a repetition rate of $500 \mathrm{pps}$ is generated in a reentrant partial coaxial cavity where the quartz sample is situated. Ultrasonic waves are then generated in the $\mathrm{x}$-quartz sample by surface excitation. The stress wave propagates through the crystal, reflects at the opposite face, returns back and a first. echo is detected by a standard superheterodyne receiver. The multiple reflections give rise to a train of echoes on the oscilloscope, corresponding to successive double trips through the specimen. Since in each round trip there is a loss of energy, mainly resulting from the attenuation of the wave in the sample, the amplitude of the echoes gradually decreases until all the energy is dissipated. An attenuation recorder automatically indicates the attenuation by comparing the amplitude of two selected echoes.

\section{Theoretical considerations}

The low temperature dynamical properties of amorphous solids and neutron-irradiated quartz can theoretically be described by the tunnelling model. According to this model, the TLS arise from the tunnelling of groups of atoms in double-well potentials. The energy difference between the two eigen-states is given by: $E^{2}=\Delta^{2}+\Delta_{0}^{2}$, where $\Delta$ is the asymmetry parameter, which describes the energy difference between the two potential minima. $\Delta_{0}$ is the tunnel splitting, also written as $\Delta_{0}=\hbar \omega e^{-\lambda}$, in which $\lambda$ describes the overlap of the wavefunctions and $\frac{\hbar \omega}{2}$ is the groundstate

energy of the particle in an isolated well. In the tunnelling model $\Delta$ and $\lambda$ are assumed to be independent of each other and to be uniformly distributed:

$$
\mathrm{P}(\Delta, \lambda) d \Delta \mathrm{d} \lambda=\overrightarrow{\mathrm{P}} \mathrm{d} \Delta \mathrm{d} \lambda \text { with } \overline{\mathrm{P}} \text { a constant. }
$$

This is one of the basic assumptions of the tunnelling model. Allthough a physical explanation for this uniform distribution is not found yet, this assumption is in good agreement with the experimental results in amorphous solids and has very recently also been verified in neutron-irradiated quartz [10].

The effect of the TLS on the low temperature ultrasonic attenuation arises from two different processes. Firstly, there is the resonant interaction between TLS and phonons. This process will not be considered here, since its contribution in this high energy experiment is negligible. The other process is the relaxational process. According to the tunnelling model, a strain wave changes the energy splittings of the asymmetric double-well potentials of the TLS. Their occupation numbers are brought out of thermal equilibrium. In glasses and also in neutron-irradiated quartz 
a return to the equilibrium state occurs via interaction with the thermal phonons. At low temperatures, the most likely process is the one phonon process, giving rise to a relaxation rate $[11]$ :

$$
\tau_{p h}^{-1}=\left(\frac{\gamma_{\ell}^{2}}{v_{\ell}^{5}}+\frac{2 \gamma_{t}^{2}}{v_{t}^{5}}\right)\left(\frac{\Delta_{0}}{E}\right)^{2} \frac{E^{3}}{2 \pi \rho \hbar^{4}} \operatorname{coth}(E / 2 k T)
$$

In this expression $\gamma_{\ell}$ and $\gamma_{t}$ represent the coupling of the TLS with the longitudinal and transverse phonons respectively. For high frequencies or very low temperatures the condition $\omega \tau_{m} \gg 1$, with $\tau_{m}$ the smallest relaxation time of the TLS, is satisfied. In this case the relaxational attenuation is frequency independent and proportional [12] to $\mathrm{T}^{3}$ :

$$
\alpha=\frac{\Pi^{3} \overline{\mathrm{P}}_{\gamma_{\ell}^{2}}^{2}}{24 \rho^{2} \hbar^{4} \mathrm{v}_{\ell}^{3}}\left(\frac{\gamma_{\ell}^{2}}{\mathrm{v}_{\ell}^{5}}+\frac{2 \gamma_{t}^{2}}{\mathrm{v}_{\mathrm{t}}^{5}}\right) \mathrm{k}^{3} \mathrm{~T}^{3}
$$

A.t lower frequencies of for higher temperatures the condition $\omega \tau_{\mathrm{m}} \ll 1$ is satisfied. For this regime the ultrasonic attenuation is temperature independent and varies linearly with frequency [12]:

$$
\alpha=\frac{\Pi \omega \overline{\mathrm{P}}_{\ell}^{2}}{2 \rho v_{\ell}^{3}}
$$

\section{Experimental results and discussion}

Fig. 1 shows the results for the longitudinal ultrasonic attenuation as a function of temperature for the sample K2N3 for a frequency of $640 \mathrm{MHz}$. The ultrasonic attenuation of an unirradiated quartz sample of the same origin, measured at the

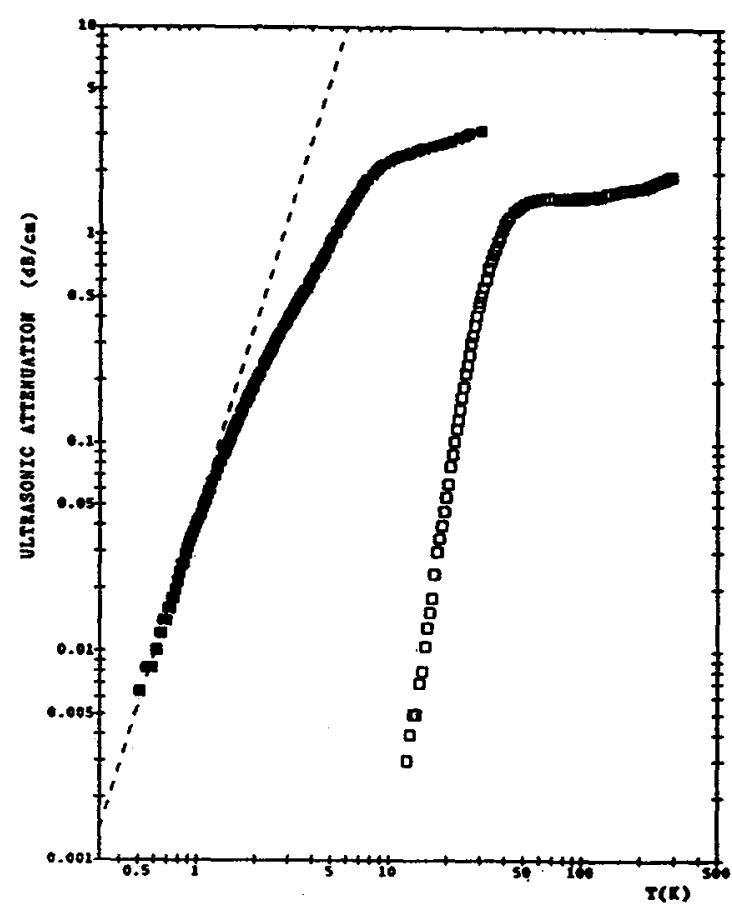
same frequency, is given for comparison. For each sample, a temperature independent residual attenuation $\alpha_{0}$, attributed to geometrical factors, was subtracted from the measured values. Indeed, the ultrasonic attenuation levels off at the lowest temperatures and for $\alpha_{0}$, a corresponding value is taken.

Fig.1.

Ultrasonic attenuation as a function of temperature for $\mathrm{f}=640 \mathrm{MHz}$

- : neutron-irradiated quartz K2N3 (dose:

$1.2 \times 10^{19} \mathrm{n} / \mathrm{cm}^{2}(\mathrm{E} \geq 0.3 \mathrm{MeV})$

$\left.2.0 \times 10^{19} \mathrm{n} / \mathrm{cm}^{2}(\mathrm{E} \geqq 0.1 \mathrm{MeV})\right)$

0 : unirradiated quartz 
At the lowest temperatures, the attenuation of the unirradiated sample is temperature independent within experimental accuracy. As can be seen in fig.1, the neutron-irradiation causes a remarkable increase of the ultrasonic attenuation compared to the unirradiated crystal. In addition, the attenuation can be described by a $\mathrm{T}^{3-}$ law. This behaviour, which is similar to that found in many glasses has been observed before in neutron-irradiated quartz [5] and very recently also in electronirradiated quartz [13]. It is typical for the relaxation attenuation due to TLS, given by expression (3).

The $\mathrm{T}^{3}$-law is only observed at the lowest temperatures. At higher temperature the attenuation levels off. In the tunnelling model this is the region where the condition $\omega \tau_{m}=1$ for the relaxation attenuation is satisfied. At about $10 \mathrm{~K}$, a shoulder is observed. A similar behaviour was found in vitreous silica for comparable frequencies [3]. It is an effect, which in the tunnelling model is attributed to the $\omega \tau_{m} \ll 1$ - regime of the relaxation attenuation and for which a $\mathrm{T}^{0}$ - attenuation is predicted. Only a shoulder is seen and not an extended $\mathrm{T}^{0}$-range because other attenuation processes become dominant in this temperature range, such as the attenuation due to the anharmonic three-phonon interaction, resulting from the remaining crystalline structure and the so-called structural relaxation attenuation $[3,14]$, well-known from amorphous solids. Above $10 \mathrm{~K}$, these processes cause a strong temperature dependent attenuation, which masks the $\mathrm{T}^{0}$-regime of the TLS.

Similar attenuation curves as that for K2N3 were obtained for the other irradiated specimens [5]. The ultrasonic attenuation was found to increase with increasing dose, which indicates that the density of states of TLS increases with dose. The attenuation was also measured for different frequencies in the range 300 to $640 \mathrm{MHz}$. It was observed that the $\mathrm{T}^{3}$-regime is frequency independent, whereas the shoulder varies linearly with frequency $[5,15]$. Both observations are in agreement with the predictions of the tunnelling model.

Making use of (4), $\overline{\mathrm{P}}_{Y \ell}^{2}$ can be determined from the height of the shoulder. The results for all the irradiated samples are given in Table 2. For each sample, the value $\overline{\mathrm{P}}_{\gamma}{ }_{l}$ is a mean value, deduced from the ultrasonic data taken for different frequencies [5]. Also $\overline{\mathbf{P}}_{\ell}^{2}$ for vitreous silica is given. It was deduced in the same way for a frequency of $105 \mathrm{MHz}$ [16]. As can be seen in Table 2, $\bar{P}_{\ell}^{2}$ is smaller than in vitreous silica and increases with increasing dose. Since the coupling parameter $\gamma_{\ell}$ of neutron-irradiated quartz is only slightly smaller than that of vitreous silica, [15] this implies that the density of states of TLS is smaller than in vitreous silica and increases with increasing dose. This was also found before [5].

Table 2 : $\overline{\mathrm{P}} \gamma_{\ell}^{2}$ versus the mass density changes

\begin{tabular}{llcccc} 
sample & $\rho\left(\mathrm{g} / \mathrm{cm}^{3}\right)$ & $\begin{array}{c}\frac{\Delta \rho}{\rho} \\
\left(\times 10^{-3}\right)\end{array}$ & $\begin{array}{c}\overrightarrow{\mathrm{P}}_{\ell}^{2} \\
\left(\times 10^{6} \mathrm{~g} / \mathrm{cm} \cdot \mathrm{s}^{2}\right)\end{array}$ \\
\hline unirradiated & 2.6499 & 0 & 0 & \\
N2 & 2.648 & 0.75 & 11 & {$[13]$} \\
N3 & 2.642 & 3.0 & $23^{*}$ & \\
K2N3 & 2.637 & 4.9 & 41 & \\
N5 & 2.623 & 10.2 & \multicolumn{2}{l}{$75^{*}$} & \\
vitreous silica & 2.203 & 168.7 & 480 & {$[16]$} \\
& & & & &
\end{tabular}

* from V. Esteves, Ph.D. thesis (1986) 
In table 2, the measured mass densities of the irradiated samples are given, as well as the relative mass density changes $\Delta \rho / \rho$ :

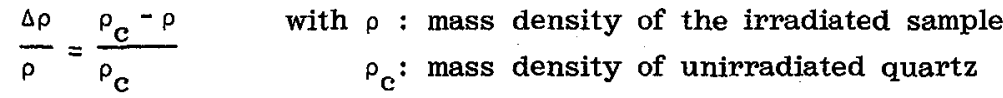

In fig. 2 the typical TLS-parameter $\overline{\mathrm{P}} \gamma_{l}^{2}$ is plotted as a function of $\Delta \rho / \rho$. Until now, there was only one other author who reported TLS-parameters in neutron-irradiated quartz samples in which also the mass density was measured [8]. It concerns a thermal study. Only one of these samples had a density change in the

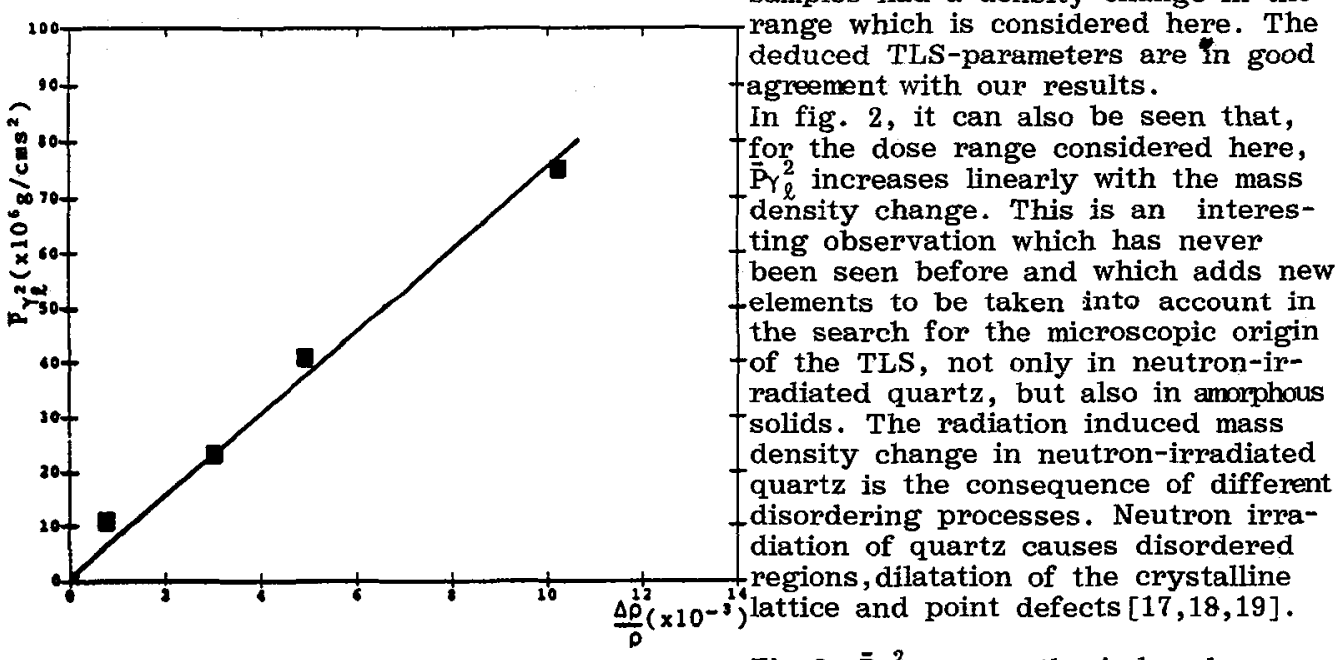

Fig. 2: $\overline{\mathrm{P}}_{l}^{2}$ versus the induced mass density change

It has been suggested before that the TLS are contained in the disordered clusters, which are thought to be most probably amorphous, but this has been contradicted however by thermal studies in neutron-irradiated quartz [8] and more recently by our ultrasonic attenuation measurements performed on electron-irradiated quartz [13] and on neutron-irradiated quartz upon heat treatment [20]. At this point it is not known how the mass density is influenced by the three disordering processes given higher. If their relative contribution to the mass density change would be known, our ultrasonic data would give more information about the location of the TLS. We also note that the linear relation between $\overline{\mathrm{P}}_{\ell}^{2}$ and $\Delta \rho / \rho$ could be closely related to the fact that, for these rather low doses, the defects are still isolated, they don't overlap. Therefore, the relation between both might be different for higher neutron doses. More experiments on high neutron doses are therefore being done.

\section{Acknowledgements}

The authors thank Dr. Groeninckx and Dr. Vandemarliere of the Department of Chemistry, K.U.Leuven, for helpful information and for supplying the equipment for the mass density measurements. Also the Oak Ridge National Laboratory (Tennessee) and especially $R$. Weeks are acknowledged for the neutron-activation analysis: They also want to thank the Belgian Interuniversitair Instituut voor Kexnwetenschappen for financial support.

\section{References}

1. P.W. Anderson, B.I.Halperin and C.M. Varma, Philos.Mag.25,1(1972); W.A. Phillips, J. Low Temp. Phys. 7, 351 (1972).

2. For a review, see Amorphous Solids: Low Temperature Properties, edited by W.A. Phillips (Springer-Verlag, Berlin 1981). 
3. S. Hunklinger and W. Arnold, in Physical Acoustics, edited by W.P. Mason and R.N. Thurston (Academic, New York, 1976), Vol.12, p.155.

4. C. Laermans, Phys. Rev. Lett. 42, 250 (1979).

5. For a recent review, see C. Laermans, in Structure and Bonding in Non-Crystalline Solids, edited by G. Walrafen and A. Revesz (Plenum, New York, 1986) p.325.

C. Laermans, V. Esteves, and A. Vanelstraete, Radiat. Eff. 97, 175 (1986). V. Esteves, Ph.D. thesis (1986).

6. B. Golding, J.E.Graebner, W.H. Haemmerle, C. Laermans, Bull. Am.Phys.Soc. 24,495 (1979).

7. A.M. de Goër, M. Locatelli, and C. Laermans, J. Phys.(Paris) Colloq. $\underline{42}$, C6-78 (1981).

C. Laermans, A.M. de Goër, and M. Locatelli, Phys.Lett. 80A, 331 (1980).

8. J.W. Gardner and A.C. Anderson, Phys.Rev. B 32, 474 (1981).

9. W. Primak, Phys. Rev., 110, 1240 (1958).

10. A. Vanelstraete, C. Laermans, L. Lejarraga, M. von Schickfus, S. Hunklinger, to be published.

11. J. Jäckle, Z. Phys. 257, 212 (1972).

12. A.K. Raychaudhuri and S. Hunklinger, Z. Phys. B $\underline{57}, 113$ (1984).

13. C. Laermans and A. Vanelstraete, Phys. Rev. B 34, 1405 (1986).

14. V. Esteves, A. Vanelstraete and C. Laermans in: Phonon Physics, Eds.J.Kollar, N. Krob , N. Menyhard, T. Siklos, Wørd Scientific, p.45 (1985).

15. C. Laermans, V. Esteves, to be published

16. S. Hunklinger (private communication).

17. D. Grasse, O.Kocar, H. Peisl, S.C. Moss and B. Golding, Phys.Rev.Lett., 46,261 (1981).

18. D. Grasse, O.Kocar, H. Peisl and S.C.Moss, Rad. Eff., 66, 61 (1982).

19. R. Comes, M. Lambert and A. Guinier, in : Interaction of radiation with solids, Ed. A. Bishey, Plenum Press, New York, p. 319 (1967).

20. C. Laermans, A. Vanelstraete, Phys. Rev. B, 15 april 1987, to be published. 